\title{
Abiotic modulators of Podocnemis unifilis (Testudines: Podocnemididae) abundances in the Peruvian Amazon
}

\author{
Darren Norris ${ }^{1,4}$; Nigel C.A. Pitmann',3; Jerry Martínez Gonzalez²; Eriberto Torres; \\ Fernando Pinto²; Hernán Collado²; Wilberth Concha²; Raúl Thupa²; Edwin Quispe; \\ Jorge Pérez ${ }^{2} \&$ Juan Carlos Flores del Castillo²
}

\author{
${ }^{1}$ Laboratório de Biologia da Conservação, Departamento de Ecologia, Universidade Estadual Paulista (UNESP), \\ Caixa Postal 199, Rio Claro, 13506-900 SP, Brazil. \\ ${ }^{2}$ Asociación para la Conservación de la Cuenca Amazónica. Jirl̀n Cusco 499, Puerto Maldonado, Madre de Dios, Peru. \\ ${ }^{3}$ Center for Tropical Conservation, Nicholas School of the Environment, Duke University. Box 90381, Durham, \\ NC 27708-0381, USA. \\ ${ }^{4}$ Corresponding author. Email: dnorris75@gmail.com
}

\begin{abstract}
Previous studies have demonstrated that river-based surveys can provide an inexpensive source of information for neotropical zoologists, yet little information is available to inform the application of this technique for the long term monitoring of neotropical turtle species. We aimed to fill this gap by presenting an assessment of data collected during 333 river surveys over 50 months along rivers in a newly protected area in the Peruvian Amazon. A total of 14,138 basking Podocnemis unifilis Troschel, 1848 were recorded during 13,510 km of river-based surveys. We used generalized additive models (GAMs) to explore the influence of a series of abiotic and seasonal variables on the recorded abundances at two temporal scales: monthly and per trip. Our analysis revealed that there was a significant increase in turtle abundances during the study period and we also found a significant seasonal periodicity in monthly abundances. Abiotic factors strongly influenced trip level abundances, with more individuals per kilometer recorded during sunny days in the dry season, with temperatures between 25 and $30^{\circ} \mathrm{C}$. The results demonstrate that turtle populations are increasing following the establishment of the protected area and that river-based surveys are likely to be more effective when carried out within a limited set of key abiotic conditions.
\end{abstract}

KEY WORDS. Basking survey; conservation; population monitoring; river turtles; sighting rates.

Lack of basic biodiversity data continues to limit global conservation efforts (Pennisi 2010, STоKSTAD 2010). Demographic parameters of wildlife populations are the foundation upon which our understanding of ecological changes are based and effective management actions for the sustainable use of wildlife populations can be developed (Noss 1990, CERTAin et al. 2011). Marine turtles are a classic example where quantifying stage specific population trends led to the application of effective management techniques and population recoveries (CROuse et al. 1987, CROWDer et al. 1994). Yet due to the time and effort required for long term population studies the quantification of demographic parameters in wildlife populations remains a challenge.

Amazonian river turtles are threatened by harvesting and the habitat loss and degradation caused by human expansion along Amazonian waterways (Mitrermeier 1978, Agostinho et al. 2005, Kemenes \& Pezzut 2007). Recently proposed changes to Brazilian legislation also pose serious threats to riparian species (Michalski et al. 2010). Generally, turtle population num- bers, demographics and population growth rates are known to be strongly dependent on the number of adults and juveniles whereas the numbers of eggs and hatchlings are relatively unimportant (Crowder et al. 1994, Garber \& Burger 1995, Heppell 1998, CHALOUPKA 2002). This pattern has also been confirmed in the Podocnemididae, including the Giant Amazonian river turtles Podocnemis expansa (Pearse et al. 2006, Mogollones et al. 2010), where for example increased hunting of adult females led to population collapses (reviewed in THORbJARNARSON et al. 2000). The longevity and population demographics of these turtles mean that monitoring the number of adults is therefore particularly critical (Mogollones et al. 2010).

Podocnemis unifilis Troschel, 1848 is classified as Vulnerable by the IUCN (Tortoise \& Freshwater Turtle Specialist Group 1996) and is listed on CITES appendix II (http://www.cites.org/ eng/app/appendices.shtml). Despite their widespread distribution throughout the Amazon basin there remains little data on $P$. unifilis abundances to enable meaningful comparison or the development of testable hypothesis for explaining why differ- 
ences in abundances exist. Behavior such as basking on logs, boulders and rocky outcrops makes $P$. unifilis one of the most common species seen during river-based boat surveys in Amazonia (PITman et al. 2011) and for the semi-aquatic $P$. unifilis river-based survey counts (sighting rates) may represent "true" counts over a known area as they are restricted to aquatic habitats (TownsEnd et al. 2005). Maximum counts from river-based surveys can therefore represent the minimum number of turtle individuals per river (Townsend et al. 2005). Yet maximum counts do not enable comparisons or hypothesis testing.

The importance of comparative data on $P$. unifilis population levels is highlighted by recent genetic studies that suggest geographically proximate populations are demographically independent units (Escalona et al. 2009a) and may therefore constitute distinct conservation management units (FranKHAM et al. 2004: 101-121). Yet few studies evaluate the use of riverbased surveys for monitoring river turtles or provide data to enable the standardization of the technique and or the generation of scientific data for basin wide comparative analysis. To contribute to the development of standardized monitoring techniques and comparative analysis of river turtles our study i) uses data collected on $P$. unifilis sighting rates (hereafter interchangeably referred to as abundances or individuals per $\mathrm{km}$ ) from an extensive river-based survey effort to identify optimum river turtle survey conditions and ii) apply a simple, reproducible modeling process to generate data applicable for comparative analysis.

\section{MATERIAL AND METHODS}

Boat surveys were conducted continuously for 50 months between April 2004 and June 2008 in the Los Amigos River watershed at the base of the Andes in southern Peru (Fig. 1). Here we present a summary of the boat survey methodology which is fully described in Pitman et al. (2011). All surveys were carried out inside the Los Amigos Conservation Concession (LACC), a 145,918-ha protected area managed by a Peruvian conservation organization since 2003 under the supervision of the Peruvian forest service. The stretches of river we surveyed included both the main stem of the Los Amigos and its largest tributary, the Amiguillos; both are low-gradient, actively meandering rivers that are born in the Amazonian lowlands and typically classified as whitewater. Survey data were grouped into three geographic sections (Fig. 1, Tab. I): I) "Lower Amigos," consisting of data collected within the $46.9-\mathrm{km}$ stretch of the Los Amigos River from its mouth to its confluence with the Amiguillos River, II) "Upper Amigos," which includes data collected within a 82.0-km stretch of the Los Amigos River upstream from its confluence with the Amiguillos River, and III) "Amiguillos," which includes data collected within a $29.7-\mathrm{km}$ stretch of the Amiguillos River upriver from its mouth.

Monitoring of $P$. unifilis was carried out by park guards as part of a broader survey of 31 faunal species (PITMAN et al. 2011). Trips were not made on a fixed schedule, but took advantage of the park guards' routine patrols and binoculars were not typi-

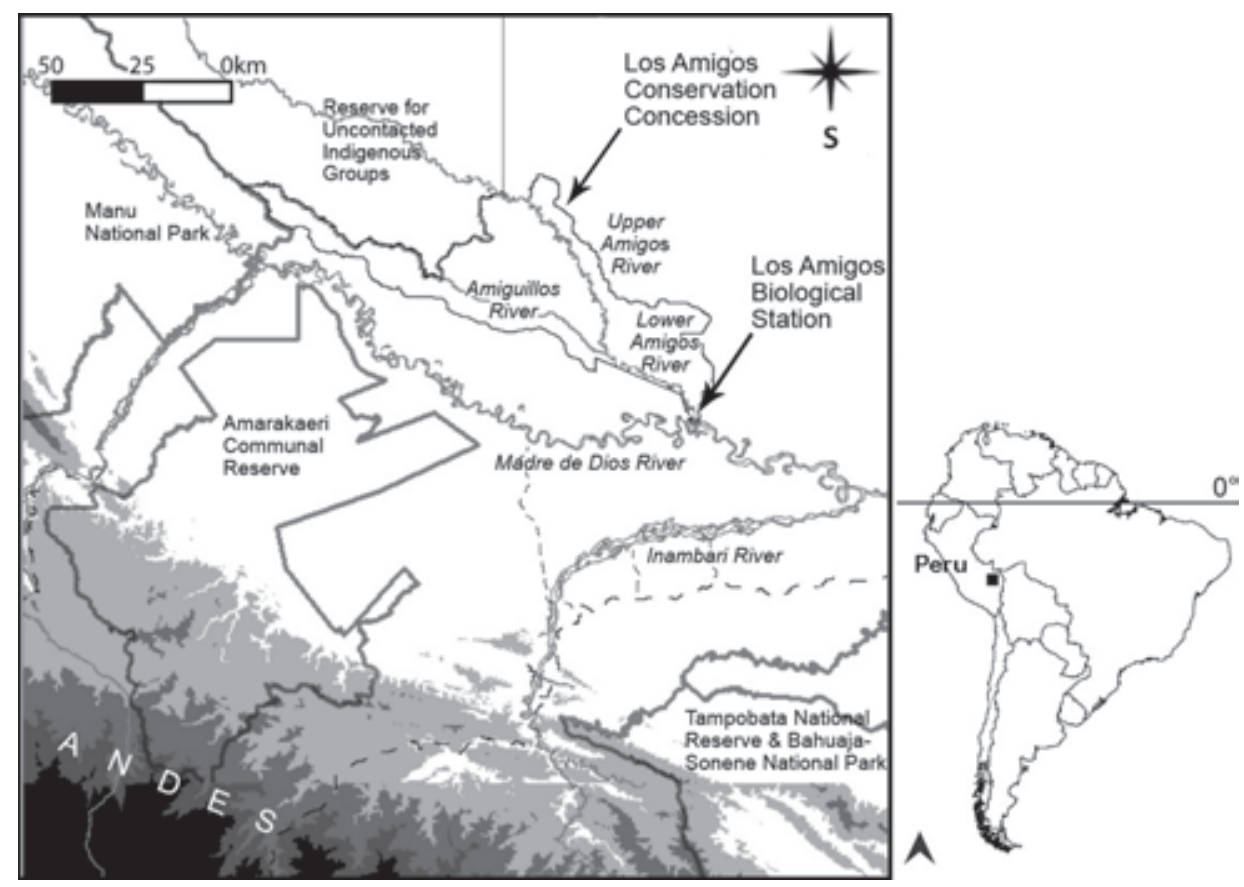

Figure 1. A map of the study area in southeastern Peru showing location of river sections surveyed. The white portion of the map is below 500 m elevation; darker gradations show 500-m intervals. Dotted lines represent roads. Several rivers have been omitted for clarity. 
Table I. Summary of boat survey sampling effort with detection rates and number of $P$. unifilis individuals recorded per kilometer along three sections of river around the Los Amigos Biological Station, Amazonian Peru.

\begin{tabular}{|c|c|c|c|c|c|}
\hline \multirow{2}{*}{$\begin{array}{c}\text { River stretch } \\
\text { [trip length km: mean, (range)] }\end{array}$} & \multirow{2}{*}{$\begin{array}{l}\text { Trips with } \\
\text { Podocnemis (\%) }\end{array}$} & \multicolumn{2}{|c|}{ Total } & \multirow{2}{*}{$\begin{array}{l}\text { Average speed } \\
(\mathrm{km} / \mathrm{h})\end{array}$} & \multirow{2}{*}{$\begin{array}{l}\text { Individuals per km } \\
\text { (range) }\end{array}$} \\
\hline & & $\mathrm{km}$ & hours & & \\
\hline Amiguillos [21.3 (19.7-29.7)] & $2 / 6(33.3)$ & 128.0 & 18.4 & 7.0 & $0.03(0-0.10)$ \\
\hline Los Amigos Lower [42.44 (7-46.9)] & $254 / 290(87.6)$ & 12307.7 & 926.3 & 13.2 & $1.17(0-10.18)$ \\
\hline Los Amigos Upper [29.0 (3.1-82.0)] & $33 / 37(89.2)$ & 1074.5 & 95.9 & 11.2 & $1.17(0-4.33)$ \\
\hline Overall [40.6 (3.1-82.0)] & $289 / 333(86.8)$ & 13510.2 & 1040.7 & 13.0 & $1.14(0-10.18)$ \\
\hline
\end{tabular}

cally used. Although the number of observers differed per trip (median $=2$, range $=1-5$ ) on each trip one guard was designated as principal observer and data recorder. Following a recent classification of monitoring approaches (DANIELSEN et al. 2008) the boat surveys can be classified as Category 3 (Collaborative Monitoring with External Data Interpretation). Park guards made an average of 7.7 trips per month (range 2-23). May and June had the highest mean number of trips, September and December the lowest. All boat travel was in 12-m wooden boats powered by $16-\mathrm{hp}$ engines with a 3-m driveshaft. Upstream velocity was $11-17 \mathrm{~km} / \mathrm{h}$; downstream velocity was $18-22 \mathrm{~km} / \mathrm{h}$.

All analyses were performed in the R-software (R DeveLopment CoRe Team 2010) with associated packages. Non-parametric tests (Wilcoxon rank sum) were used to compare abundances (individuals per $\mathrm{km}$ ) recorded during trips along the three river sections. To quantify the influences of series of abiotic and seasonal variables on monthly and trip level abundances we used generalized additive models (GAMs, package "mgcv" (Wood 2010)) to model the number of individuals recorded per km. Previous studies have demonstrated that GAMs are particularly suited to modelling irregular time-series data such as ours (Simpson \& ANDERSON 2009). With GAMs it is possible to model a combination of parametric variables (as commonly carried out in generalized linear models) and non-parametric "smoothed" variables, which allows the shape of the relationship between the response and the explanatory variables to be determined from the data, rather than following a prescribed functional form (e.g. linear). As a result, GAMs are able to model non-linear relationships between the response and the covariates, with the effect of the covariate varying across its range (Wood 2008).

To quantify influences on the month to month variation in the response of $P$. unifilis abundances (for each month the total individuals from all trips/total survey $\mathrm{km}$ ) a total of 4 weakly correlated (maximum Spearman correlation $r=0.49$, across all pairwise comparisons) continuous variables were included as non-parametric smoothed predictors in a GAM, built using the package defaults for obtaining model knots and smoothing parameters. We used "month" (continuous values 1 to 50 ) to model the non-linear trends in abundances, mean river level was derived from daily records for the river level relative to an arbitrary fixed point established on the bank of the Madre Dois river (data and recording details available from: http://atrium.andesamazon.org/meteo_station_display_ info.php?id =14). Abiotic conditions were measured by mean air temperature and total precipitation per month, both of which were derived from daily records at the weather station at the Los Amigos Biological Station, near the mouth of the Los Amigos River (data and weather station details available from: http://atrium.andesamazon.org/meteo_station_display_ info.php?id = 12). For 5 months (April to August 2004) temperature and precipitation data were obtained from manual records at the Los Amigos Biological Station (data and recording details available from: http://atrium.andesamazon.org/ meteo_station_display_info.php?id=13). These variables were selected as previous studies have shown their importance in relation to observed sighting rates and abundances (Townsend et al. 2005, Coway-Gomez 2007, Escalona et al. 2009b).

To evaluate modulators of trip level abundances and obtain estimates of optimum survey conditions we used 8 variables (data sources as per monthly abundances unless otherwise stated) to explain the variation in the response of the number of individual $P$. unifilis per $\mathrm{km}$ seen during a trip in a GAM. The mean air temperature during the trip (for 18 trips from April to August 2004 where weather station data was not available we used manually recorded maximum daily values), water level (daily mean) and two categorical factors of sunlight and rain (binary presence and absence) recorded during the trip were used to model abiotic conditions that are known to influence P. unifilis activity (Townsend et al. 2005, Coway-Gomez 2007, Escalona et al. 2009b). We also included a continuous linear measure of time to test for a temporal trend (i.e. a significant increase over time) in the observed abundances, plus two additional categorical factors that are also likely to explain variation in sighting records from our boat surveys: trip start period (i.e. 4 classes representing the time of day during which a trip was started) was included as detections of $P$. unifilis from boat surveys are strongly related to the time of day (CowAY-Gomez 2007) and finally observers. To test for an observer effect we retained as individual levels in our categorical factor only those observers $(n=5)$ who had a minimum experience of 23 trips and 2.5 years of surveys. Results from all other observers (a 
total of 45 trips) were grouped together into one "less experienced" class. We did not include the total number of observers per trip (range 1-5) as it was the single designated observer who had primary responsibility for counting species and there was no significant influence of the total number of observers (categorical factor with 5 levels: 1-5) on $P$. unifilis abundances per trip (ANOVA, $\mathrm{F}=1.679_{4,328^{\prime}} \mathrm{p}=0.154$ ).

We used an information theoretic model averaging framework (BURNHAM \& ANDERSON 2002) to examine the influences of the 8 variables on the $P$. unifilis abundances recorded per trip. This approach enables multimodel inference where our GAM models are ranked and scaled by some information criterion to allow an understanding of model uncertainty over the set of candidate models (Burnham \& ANDERson 2002: 281-284). We evaluated models based on their information content, as measured by AIC (Akaike Information Content implemented in R package "MuMIn" (BARTON 2011)). With a strong a priori justification for inclusion, we retained all predictors and all possible candidate models; therefore, all predictors were on equal footing to calculate their relative importance as measured by variable Akaike weights (BURNHAM \& ANDERSON 2002: 75-77, 167 $172)$, which is a scaled measure of the likelihood ratio that ranges between 0 (least important) and 1 (most important). A reduced subset of models for a $95 \%$ confidence set, based on the sum of Akaike weights across all models from largest to smallest that resulted in the sum of $\leqslant 0.95$, was used to calculate average values for slopes (BurnhAM \& ANDERson 2002: 169, 176-177). To reduce model selection bias model averaging was carried out using the full set of confidence models i.e. when a predictor was not present in the model its value was set to 0 (Burnham \& ANDERSON 2002, pp. 152).

\section{RESULTS}

Park guards recorded a total of 14138 individual $P$. unifilis over 50 months of surveys. Although the number of trips differed per month there was no significant correlation between the monthly abundances (total individuals/total km surveyed) recorded and the monthly total survey $\mathrm{km}$ (Spearman's rank correlation, $r=0.01$ ), which indicates that the effort per month was sufficient to ensure that differences in total kilometers surveyed did not influence the recorded abundances. Overall an average of 1.05 individual $P$. unifilis was recorded per $\mathrm{km}$ of river. Pairwise comparisons of individuals per km between trips on the three survey sections revealed that Amiguillos could be considered distinct from the Lower and Upper Amigos in terms of $P$. unifilis abundances. There was a significantly lower abundance on the Amiguillos when compared with Lower and Upper Amigos (Wilcoxon rank sum test, $p=0.0007, p=0.001$, Lower and Upper Amigos respectively). Although mean values between the "Upper" and "Lower" regions of the Los Amigos river were the same (Tab. I), median values were higher in the Upper Amigos (0.90 compared with 0.75 individuals per km,
Upper and Lower respectively) suggesting a slight but insignificant (Wilcoxon rank sum test, $\mathrm{p}=0.53$ ) increase in abundances along the Upper region.

There was a strong non-linear seasonal pattern in abundances, with more individuals per $\mathrm{km}$ recorded during trips in the dry season (Tab. II) and peak monthly abundances occurring when the river levels were declining or at their lowest (Fig. 2 ). Results from our GAM model showed that monthly abundances increased with time (Fig. 2, p = 0.012). The upper 95\% confidence interval of the GAM model of monthly abundances provided the following minimum annual abundance (individuals per $\mathrm{km}$ ) estimates along the $158.6 \mathrm{~km}$ of survey rivers: 1.74 (August 2004), 1.83 (July 2005), 2.44 (July 2006), and 2.56 (August 2008). These results from our GAM model provide values that correspond to an estimated $47 \%$ increase in the minimum number of turtles across the watershed from 276 individuals in 2004 to 406 in 2008. Although none of the other three variables (river level, mean temperature and total precipitation) were significant at the $95 \%$ level, comparisons of model AIC values (lower values indicate a relatively better model) showed that removing these "non-significant" variables did not substantially improve the model (AIC values: 94.67, 93.27, 94.04, 107.82 for the full model, and excluding river level, total precipitation and mean temperature respectively) as differences in AIC less than four are unlikely support any particular model (BURNHAM \& ANDERSON 2002: 170) i.e. all variables are important to model the monthly $P$. unifilis abundances.

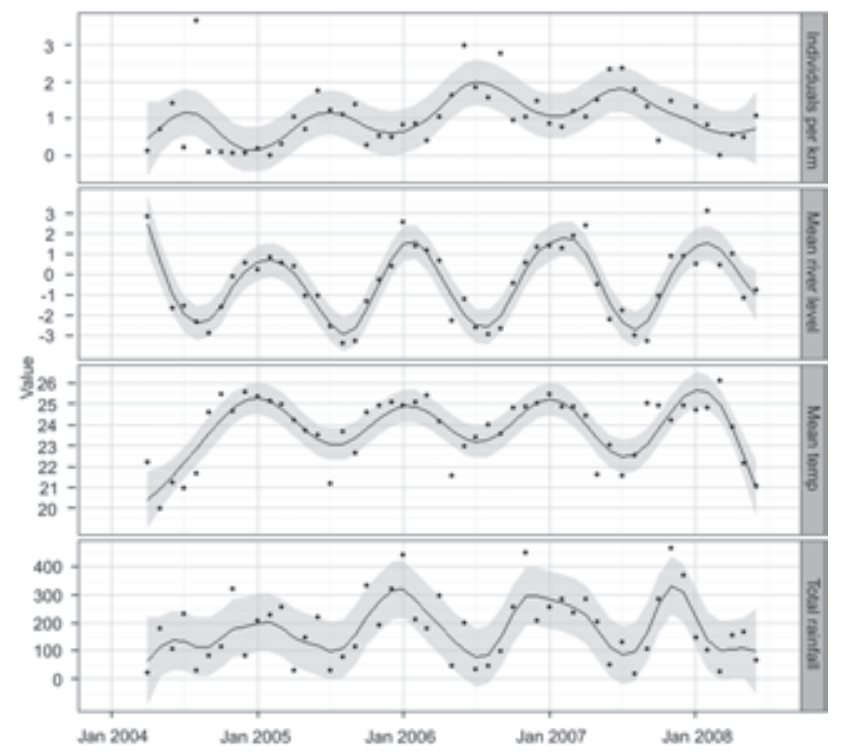

Figure 2. Monthly patterns in P. unifilis abundances and abiotic factors around the Los Amigos Biological Station, Amazonian Peru, from April 2004 to August 2008. Solid black lines and grey shaded areas show predicted values and confidence intervals obtained from generalized additive models, grey dots are the observed values. 
Table II. Model weights and parameter (slope) estimates from information-theoretic analysis of predictors of the occurrence of $P$. unifilis monitored during four years of boat surveys. Generalized additive models were used to predict the abundance (individuals per km) recorded during 333 trips around the Los Amigos Biological Station, Amazonian Peru.

\begin{tabular}{|c|c|c|}
\hline \multirow{2}{*}{ Model factor } & \multicolumn{2}{|c|}{ Individuals per kilometer } \\
\hline & $\sum w_{i}(\text { rank })^{a}$ & Slope (SE) \\
\hline Temporal trend & $0.83(2)$ & $\times 0.134(0.074)$ \\
\hline River level & $1.00(1)$ & $-0.062(0.050)$ \\
\hline Sun (trips with compared to trips without) & $1.00(1)$ & $* * * 0.695(0.161)$ \\
\hline Season (wet compared with dry) & $1.00(1)$ & $*^{*}-0.544(0.181)$ \\
\hline Rain (trips with compared to trips without) & $1.00(1)$ & $* * *-0.722(0.213)$ \\
\hline Mean trip temperature ${ }^{s}$ & $1.00(1)$ & \\
\hline Observer (compared with most experienced) & $0.10(3)$ & \\
\hline 2 & & $0.252(0.212)$ \\
\hline 3 & & $0.146(0.215)$ \\
\hline 4 & & $-0.121(0.221)$ \\
\hline 5 & & $-0.386(0.300)$ \\
\hline 6 & & $0.150(0.243)$ \\
\hline Start period (compared with start before 08:00) & $1.00(1)$ & \\
\hline $8-10: 59$ & & ***0.739 (0.191) \\
\hline $11: 00-13: 59$ & & **0.710 (0.249) \\
\hline After 13:59 & & *0.749 (0.307) \\
\hline
\end{tabular}

Parameter significance: ${ }^{* *}<0.001,{ }^{* *}<0.01,{ }^{*}<0.05,{ }^{*}<0.1$.

a The sum of Akaike weights for all models within our set of candidate models with a given variable. Model averaging was carried out using the full set of confidence models, i.e., when a predictor was not present in the model its value was set to 0 (BURNHAM \& ANDERSON 2002: 152).

${ }^{s}$ Non-parametric smoothed term.

At the trip level, seven of our eight explanatory variables provided important information content as demonstrated by the sum of Akaike weights and or were statistically significant in explaining the number of individual $P$. unifilis seen per $\mathrm{km}$ (Tab. II), with "Observer" being the only insignificant variable. Based on the results from our trip level analysis (Tab. II), the optimum conditions for conducting surveys of river turtles were: during the dry season, with sun and no rain, trip start times between 08:00 and 14:00 $\mathrm{h}$, and temperatures ranging between 25 and $30^{\circ} \mathrm{C}$. Visual inspection of mean abundances (number of individuals per kilometer) seen per hour showed that higher than average abundances were seen during trips that started after 8:00 and finished before $16: 00 \mathrm{~h}$ and that the highest abundances were recorded during trips that started after 10:00 but finished before 13:00 h (Fig. 3).

\section{DISCUSSION}

Our analysis reveals important aspects relating to the use of river-based surveys for monitoring neotropical freshwater turtle populations. Previous studies have demonstrated that

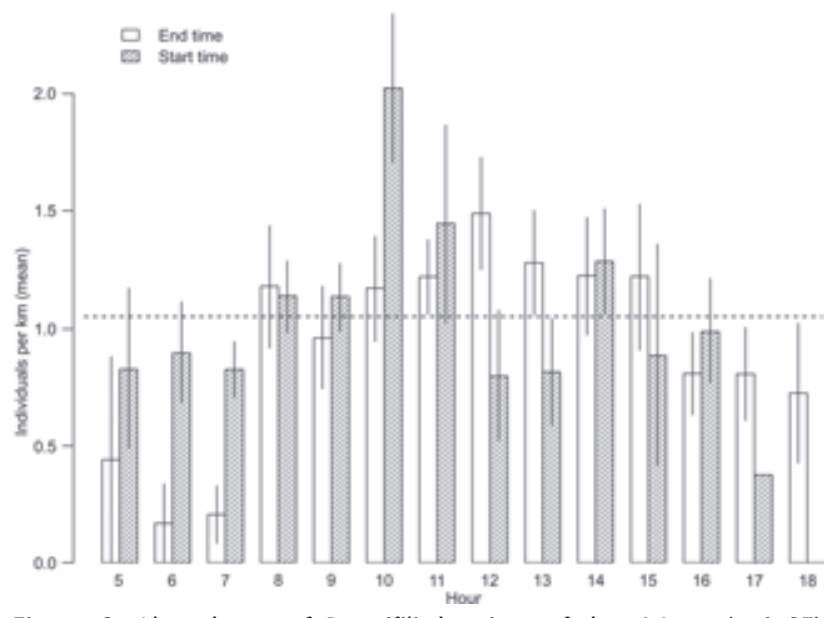

Figure 3. Abundance of $P$. unifilis by time of day. Mean ( $\pm 1 \mathrm{SE}$ ) abundances (individuals per kilometer) recorded by trip start (lined bars) and end times (open bars) during 333 river-based surveys around the Los Amigos Biological Station, Amazonian Peru, from April 2004 to August 2008. The dashed horizontal line is the average abundance recoded from all trips. 
river-based surveys can provide an inexpensive source of information for neotropical zoologists (PITMAN et al. 2011), here we add information that we hope will encourage and facilitate both the use and standardization of this monitoring approach on a wider scale.

Our observed maximum abundances from the most completely surveyed Lower and Upper sections (10.18 and 4.33 individuals per $\mathrm{km}$ respectively) are within the range of those previously reported. During 5 years of surveys along 2 rivers (28 and $20 \mathrm{~km}$ ) in Ecuador and reporting values that included "mostly" P. unifilis, Townsend et al. (2005) found maximum abundances of 7.00 and 20.55 individuals per km. By combining observations of both $P$. unifilis and $P$. expansa from a total of 960 river-based survey $\mathrm{km}$ along three $40 \mathrm{~km}$ transects on two rivers in lowland eastern Bolivia COWAY-GOMEz (2007) found maximum abundances of 1.93, 2.45 and 12.53 individuals per $\mathrm{km}$. Previous studies from the northern Peruvian Amazon reported 14 individual $P$. unifilis per km (SorN 1996). Based on these results it appears that along lowland, lower order rivers across the Amazon basin maximum abundances in the region of 2-20 individual $P$. unifilis per $\mathrm{km}$ of river can be expected. Although there is considerable variation in reported maximum abundances, what is clear is that these abundances represent decimated populations compared with accounts from early Amazon explorers (Medina 1934, Mittermeier 1978, Johns 1987).

Our monthly analysis confirms previous studies that reported strong seasonal influences on the distribution and sighting rates of $P$. unifilis (Townsend et al. 2005, Balensiefer \& VogT 2006, Escalona et al. 2009b), which due to dramatic seasonal fluctuations in water levels are thought to be confined to permanent rivers and waterways during the dry season but during the wet season disperse into perennially flooded forest regions. Seasonality of water levels also influences the detectability of river turtles as during the dry season there is an increase in the availability of logs, rocks and beaches which may be used for basking. Additionally female $P$. expansa increase basking activity prior to nesting which coincides with low water levels during the dry season (von Hildebrand et al. 1988), although this behavior has not been reported for $P$. unifilis it is possible that $P$. unifilis will also demonstrate behaviors that influence detectability. Previous studies have also demonstrated how abundances of $P$. unifilis and $P$. expansa differ spatially in relation to anthropogenic pressure (CowAY-Gomez 2007). Our results also suggest that there are spatial differences in abundances along the river sections studied. Yet, as we did not record differences in the density of suitable basking points we are unable to make any inference regarding why abundances on the Lower and Upper sections were the same and statistically higher than those recorded during trips on the Amiguillos. Further studies that develop standardized monitoring protocols for river turtles, specifically evaluating how the temporal and spatial distribution of potential basking points influences detectability and resulting abundance estimates are required before any firm conclusions can be drawn relating to potential modulators of the spatio-temporal distribution of $P$. unifilis.

As expected based on the physiological constraints that limit the activity of the ectothermic $P$. unifilis we found that a series of abiotic factors had a significant influence on the observed trip level abundances. Although it is not possible to disentangle the effects of I) differences in detection probability and II) spatio-temporal patterns in the distribution of $P$. unifilis, we were able to establish some key thresholds that provide for optimum sampling conditions. Highest abundances were found on warm $\left(25-30^{\circ} \mathrm{C}\right)$, sunny days during the dry season during trips that started after 8:00 h but finished before 16:00 h. For neotropical zoologists that often have limited time and financial resources these conditions are likely to provide the most cost effective for studies that aim to quantify river-based abundances of $P$. unifilis.

Although river-based surveys have long been recognized as a relatively accurate source of population information compared with hand or hoop net based techniques (KоPER \& BROOKS 1988) little use has been made of the technique by neotropical zoologists. We found that using park guard observers provided data that can be used for basin wide comparisons of river turtle populations. We believe that modeling the observed sighting rates has several advantages over simply presenting maximum counts as proposed by Townsend et al. (2005). Maximum values are inherently biased by survey intensity, observer, weather, and location specific detectability (i.e. river width, density of logs, boulders, and beaches). Therefore, although maximum counts may provide a minimum estimate for a particular section of river at a particular time they do not allow comparison of abundances or population trends between different rivers/ watersheds across the Amazon basin. By applying a simple and freely available modeling approach we provide data relating to $P$. unifilis populations that are suitable for such future comparisons. There do however exist limitations: I) basking surveys are obviously not appropriate for nocturnal turtle species, II) the ability to reliably identify different turtle species, for example (Coway-Gomez 2007) had to combine data from sympatric $P$. unifilis and $P$. expansa due to difficulties in separating the species, and III) the use of river-based monitoring to provide reliable stage specific (e.g. juveniles compared with adults) abundance estimates remain untested. Recently geometric morphometric analysis of carapaces was used to successfully identify the gender of $P$. expansa hatchlings (Lubiana \& Dias FERREIRA JÚNIOR 2009). Investigations into the application of similar morphometric analysis for the separation of species, age classes and gender from photos obtained during boat surveys may provide cost effective solutions to these limitations.

The use of park guards/community based monitors is one of the strongest benefits (community involvement, active participation and increased motivation (Townsend et al. 2005, Danielsen et al. 2008, Pitman et al. 2011)) and potential weaknesses (relative lack of training compared with "specialized" 
scientific researchers) of our monitoring approach (DANIELSEN et al. 2008). By integrating the considerable volume of data collected with "expert" analysis we confirm that it is possible to provide reliable, comparative and cost effective data on neotropical turtle populations.

\section{ACKNOWLEDGEMENTS}

The field work described in this paper was funded by a grant from the Gordon and Betty Moore Foundation to the Amazon Conservation Association and its Peruvian sister organization, the Asociación para la Conservación de la Cuenca Amazónica. Additional funding was provided by a Rufford Small Grant for Nature Conservation to NCAP. DN receives a fellowship from CNPq. We appreciate the support of the Peruvian park service, which authorized this research as part of the LACC's management plan. We thank Nelson Gutiérrez for the base map in Fig. 1 and two anonymous reviewers for comments that improved an earlier version.

\section{LITERATURE CITED}

Agostinho, A.A.; S.M. Thomaz \& L.C. Gomes. 2005. Conservation of the biodiversity of Brazil's inland waters. Conservation Biology 19 (3): 646-652. doi: 10.1111/j.1523-1739.2005.00701.x.

Balensiefer, D.C. \& R.C. Vogt. 2006. Diet of Podocnemis unifilis (Testudines, Podocnemididae) during the dry season in the Mamiraua Sustainable Development Reserve, Amazonas, Brazil. Chelonian Conservation and Biology 5 (2): 312-317. doi: 10.2744/1071-8443(2006)5[312:DOPUTP]2.0.CO;2.

BARTON, K. 2011. MuMIn: Multi-model inference version 1.0.0/r75. Available online at: http://R-Forge.R-project.org/ projects/mumin [Accessed: 23.I.2011].

Burnham, K.P. \& D.R. Anderson. 2002. Model Selection and Multi-Model Inference: A Practical InformationTheoretic Approach. New York, Springer, 496p.

Certain, G.; O. Skarpaas; J-W. Bjerke; E. Framstad; M. Lindholm; J-E. Nilsen; A. Norderhaug; E. Oug; H-C. Pedersen; A-K. Schartau; G.I. van der Meeren; I. Aslaksen; S. Engen; P-A. Garnåsjordet; P. Kvaløy; M. LILlegård; N.G. YocCoZ \& S. Nybø. 2011. The Nature Index: A general framework for synthesizing knowledge on the state of biodiversity. PLoS ONE 6 (4): e18930. doi: 10.1371/ journal.pone.0018930.

Chaloupka, M. 2002. Stochastic simulation modelling of southern Great Barrier Reef green turtle population dynamics. Ecological Modelling 148 (1): 79-109. doi: 10.1016/S0304-3800(01)00433-1.

Coway-Gomez, K. 2007. Effects of human settlements on abundance of Podocnemis unifilis and P. expansa turtles in Nortbeastern Bolivia. Chelonian Conservation and Biology 6 (2): 199-205. doi: 10.2744/1071-8443(2007)6[199:EOHSOA]2.0.CO;2.

Crouse, D.T.; L.B. Crowder \& H. Caswell. 1987. A stage-based population model for loggerhead sea turtles and implications for conservation. Ecology 68 (5): 1412-1423. doi: 10.2307/ 1939225.

Crowder, L.B.; D.T. Crouse; S.S. Heppell \& T.H. Martin. 1994. Predicting the impact of turtle excluder devices on Loggerhead Sea-turtle populations. Ecological Applications 4 (3): 437-445. doi: 10.2307/1941948.

Danielsen, F.; N.D. Burgess; A. Balmford; P.F. Donald; M. Funder; J.P.G. Jones; P. Alviola; D.S. Balette; T. Blomley; J. Brashares; B. Child; M. Enghoff; J. FJeldsa; S. Holt; H. Hubertz; A.E. Jensen; P.M. Jensen; J. Massao; M.M. Mendozz; Y. Ngaga; M.K. Poulsen; R. Rueda; M. Sam; T. Skielboe; G. Stuart-Hill; E. Topp-Jørgensen \& D. Yonten. 2008. Local participation in natural resource monitoring: a characterization of approaches. Conservation Biology 23 (1): 31-42. doi: 10.1111/j.1523-1739.2008.01063.x.

Escalona, T.; T.N. Engstrom; O.E. Hernandez; B.C. Bock; R.C. Vogt $\&$ N. ValenZuela. 2009a. Population genetics of the endangered South American freshwater turtle, Podocnemis unifilis, inferred from microsatellite DNA data. Conservation Genetics 10 (6): 1683-1696. doi: 10.1007/s10592-008-9746-3.

Escalona, T.; N. Valenzuela \& D.C. Adams. 2009b. Nesting ecology in the freshwater turtle Podocnemis unifilis: spatiotemporal patterns and inferred explanations. Functional Ecology 23 (4): 826-835. doi: 10.1111/j.1365-2435.2009.01562.x.

Frankham, R.; J.D. Ballou \& D.A. Briscoe. 2004. A Primer of Conservation Genetics. Cambridge, Cambridge University Press, 236p.

Garber, S.D. \& J. Burger. 1995. A 20-yr study documenting the relationship between turtle decline and human recreation. Ecological Applications 5 (4): 1151-1162. doi: 10.2307/2269362.

Heppell, S.S. 1998. Application of life-history theory and population model analysis to turtle conservation. Copeia (2): 367-375.

Johns, A.D. 1987. Continuing problems for Amazon river turtles. Oryx 21 (1): 25-28. doi: 10.1017/S0030605300020445.

Kemenes, A. \& J.C.B. Pezzut. 2007. Estimate of trade traffic of Podocnemis (Testudines, pedocnemididae) from the middle Purus River, Amazonas, Brazil. Chelonian Conservation and Biology 6 (2): 259-262. doi: 10.2744/1071-8443(2007)6 [259:EOTTOP]2.0.CO;2.

Koper, N. \& R.J. Brooks. 1988. Population-size estimators and unequal catchability in painted turtles. Canadian Journal of Zoology 76 (3): 458-465. doi: 10.1139/z97-220.

Lubiana, A. \& P. Dias Ferreira Júnior. 2009. Pivotal temperature and sexual dimorphism of Podocnemis expansa hatchlings (Testudines: Podocnemididae) from Bananal Island, Brazil. Zoologia 26 (3): 527-533. doi: 10.1590/S1984-46702009000300016.

Medina, J. 1934. The discovery of the Amazon according to the account of Friar Caspar de Carvajal (Oveido's version), p. In H.C. Heaton (Ed.). Special Publication 17. New York, American Geographical Society.

Michalski, F.; D. Norris \& C.A. Peres. 2010. No return from biodiversity loss. Science 329 (5997): 1282-1282. doi: 10.1126/science.329.5997.1282-a. 
Mittermeier, R.A. 1978. South America's river turtles: saving them by use. Oryx 14 (3): 222-230. doi: 10.1017/ S0030605300015532.

Mogollones, S.C.; D.J. Rodriguez; O. Hernandez \& G.R. Barreto. 2010. A demographic study of the arrau turtle (Podocnemis expansa) in the Middle Orinoco River, Venezuela. Chelonian Conservation and Biology 9 (1): 79-89. doi: 10.2744/CCB0778.1.

Noss, R.F. 1990. Indicators for monitoring biodiversity: A hierarchical approach. Conservation Biology 4 (4): 355364. doi: 10.1111/j.1523-1739.1990.tb00309.x.

Pearse, D.E.; A.D. Arndt; N. Valenzuela; B.A. Miller; V. Cantarelli \& J.W. Sites. 2006. Estimating population structure under nonequilibrium conditions in a conservation context: continent-wide population genetics of the giant Amazon river turtle, Podocnemis expansa (Chelonia; Podocnemididae). Molecular Ecology 15 (4): 985-1006. doi: 10.1111/j.1365294X.2006.02869.x.

Pennisi, E. 2010. Filling gaps in global biodiversity estimates. Science 330 (6000): 24-24. doi: 10.1126/science.330.6000.24.

Pitman, N.C.A.; D. Norris; J. Martinez Gonzalez; E. Torres; F. Pinto; H. Collado; W. Concha; R. Thupa; E. Quispe; J. Perez \& J.C. Flores DEL CASTILlo. 2011. Four years of vertebrate monitoring on an upper Amazonian river. Biodiversity and Conservation 20 (4): 827-849. doi: 10.1007/s10531-010-9982-y.

R Development Core Team. 2010. R: A language and environment for statistical computing version 2.12.1. Available online at: http://www.R-project.org/. [Accessed: 20.XII.2010].

Simpson, G.L. \& N.J. Anderson. 2009. Deciphering the effect of climate change and separating the influence of confounding factors in sediment core records using additive models.
Limnology and Oceanography 54 (6): 2529-2541. doi: 10.4319/lo.2009.54.6_part_2.2529.

Solni, P. 1996. Reproducción, abundancia y situación de quelonios acuáticos en la Reserva Nacional Pacaya-Samiria, Perú. Folia Amazonica 8 145-155.

StOKSTAD, E. 2010. Despite progress, biodiversity declines. Science 329 (5997): 1272-1273. doi: 10.1126/science.329.5997.1272.

Thorbjarnarson, J.B.; C.J. Lagueux; D. Bolze; M.W. Klemens \& A.B. MeYLAN. 2000. Human use of turtle: a worldwide perspective, p. 33-84. In M.W. KLEMENs (Ed.). Turtle Conservation. Washington, DC, Smithsonian Institution Press.

Tortoise \& Freshwater Turtle Specialist Group. 1996. Podocnemis unifilis. In: IUCN 2010. IUCN Red List of Threatened Species version 2010.4. Availeable online at: http:// www.iucnredlist.org. [Accessed: 15.V.2011].

Townsend, W.R.; R. Borman; E. Yiyoguaje \& L. Mendua. 2005. Cofan Indians' monitoring of freshwater turtles in Zabalo, Ecuador. Biodiversity and Conservation 14 (11): 27432755. doi: 10.1007/s10531-005-8410-1.

von Hildebrand, P.; C. Saenz; M.C. Penuela \& C. Caro. 1988. Biolog1a y conservacion de la tortuga charapa Podocnemis expansa en el R1o Caqueta en Amazonas, Colombia. Bogota, Colombia, Fundacion Puerto Rastrojo, 85p.

Wood, S.N. 2008. Fast stable direct fitting and smoothness selection for generalized additive models. Journal of the Royal Statistical Society (B) 70 (3): 495-518. doi: 10.1111/ j.1467-9868.2007.00646.x.

Wood, S.N. 2010. mgcv: GAMs with GCV/AIC/REML smoothness estimation and GAMMs by REML/PQL version 1.7-2. Available online at: http://CRAN.Rproject.org/package $=$ mgcv. [Accessed: 22 December 2010] .

Submitted: 25.IV.2011; Accepted: 22.V.2011.

Editorial responsibility: Heraldo L. de Vasconcelos 